\title{
ARTIGOS
}

\section{ESTUDO DE RECICLABILIDADE E REUTILIZAÇÃO DE CÁPSULAS POLIMÉRICAS DE CAFÉ}

\section{STUDY OF RECYCLABILITY AND RE-USE OF POLYMERIC COFFEE CAPSULES}

\author{
AMANDA MELCHIORS|UFSM \\ ANA PAULA PALHANO|UFSM \\ MARIANA KUHL CIDADE, Dra.| UFSM
}

\begin{abstract}
RESUMO
Um dos problemas ambientais enfrentados atualmente é o grande volume de embalagens sem potencial de reciclabilidade. Estas acabam tendo este destino devido a fatores como multimateriais e excesso de impurezas. A exemplo, são as capsulas de café poliméricas, com potencial para a reciclagem, e que contém em seu interior, após o uso, rejeitos orgânicos. Estes, deveriam ser retirados, pelos consumidores, antes do descarte no lixo, mas muitas vezes, isto não é feito, dificultando assim a reciclagem. Com isto, este artigo tem como objetivo uma possível conscientização aos consumidores que geram este tipo de resíduo e mostrar que é possível a reciclagem e/ou reutilização destes resíduos. Com a destinação certa, cápsulas de café podem e devem ser recicladas ou reutilizadas, gerando possíveis aplicações em novos produtos. Foram efetuados testes para a verificação de temperatura de fundição, e como resultado final foi possível desenvolver dois projetos de adornos sustentáveis.
\end{abstract}

PALAVRAS CHAVE: Sustentabilidade, reciclagem; reutilização; conscientização; design

\begin{abstract}
One of the environmental problems faced today is the large volume of packaging with no potential for recyclability. These end up having this destiny due to factors such as multimaterials and excessive impurities. For example, they are polymeric coffee capsules, with potential for recycling, and which contain, after use, organic waste. These should be removed by consumers before being disposed of in the garbage, but often this is not done, thus making recycling difficult. With this in mind, this article aims to raise awareness among consumers who generate this type of waste and show that it is possible to recycle and / or reuse this waste. With the right destination, coffee capsules can and should be recycled or reused, generating possible applications in new products. Tests were carried out to verify the casting temperature, and as a final result it was possible to develop two sustainable adornment projects.
\end{abstract}

KEYWORDS: Sustainability, recycling; reuse; awareness; design 


\section{INTRODUÇÃO}

Enquanto o mundo avança em direção a padrões mais modernos e sustentáveis de gestão de resíduos, o Brasil continua apresentando deficiências, ficando abaixo dos indicadores médios de nações da mesma faixa de renda e desenvolvimento (ABRELPE, 2019). Segundo a Associação Brasileira de Empresas de Limpeza Pública e Resíduos Especiais (2019), ao nos aproximarmos do início de mais uma década, percebe-se que pouco foi desenvolvido e feito com o objetivo de realmente reverter o quadro deficitário no Brasil. Mesmo com as ações feitas até o momento, o país ainda é carente em alguns aspectos, tanto por questões sociais e políticas, mas principalmente feitios culturais.

Com o aumento do consumo demasiado de produtos por parte da população, sejam eles eletroeletrônicos, alimentos embalados, móveis, vestuário, entre outros, tem gerado um acúmulo de descarte destes em aterros sanitários, lixões, e locais indesejados, o que consequentemente leva à problemas ambientais (CARVALHO; XAVIER, 2014; BARELLI, 2009).

O lixo doméstico no Brasil é chamado de resíduos sólidos urbanos (RSU) e segundo a Política Nacional de Resíduos Sólidos (PNRS), Lei 12.305/2010, estes en-tende-se por componentes que sobram de proces $\neg$ sos derivados das atividades humanas e animal e de processos produtivos, tais como lixo doméstico, os efluentes industriais e os gases liberados (BRASIL, 2010). Esta também orienta uma categoria de ações a serem seguidas na gestão e no gerenciamento dos RSU, onde uma das prioridades é a reciclagem e a reutilização. Entende-se por reciclagem todo o processo de transformação de resíduos que envolve a alteração de propriedades físicas, físico-químicas ou biológicas e que dá origem a novos insumos ou novos produtos; e reutilização é a prática de aproveitar os resíduos sem modificar as suas propriedades.

De acordo com a ABRELPE (2019), no ano de 2018, o Brasil gerou cerca de 79 milhões de toneladas de RSU, ou 216.629 toneladas/dia, sendo que desse montante, 92\% foi recolhido. Estimando o aumento da população, isso significa que, em média, cada brasileiro gerou pouco mais de 1 quilo de resíduo por dia (ABRELPE, 2019). Evidenciase também, no panorama relatado pela Associação Brasileira de Empresas de Limpeza Pública e Resíduos Especiais (2019), que 6,3 milhões de toneladas de resíduos não foram recolhidas junto aos locais de geração. A destinação adequada em aterros sanitários recebeu 59,5\% dos resíduos sólidos urbanos coletados, e o restante (40,5\%) foi despejado em locais inadequados por 3.001 municípios (ABRELPE, 2019). Ou seja, 29,5 milhões de toneladas de RSU acabaram indo parar em lixões, que não contam com um conjunto de sistemas e medidas necessários para proteger a saúde das pessoas e o meio ambiente contra danos e degradações (ABRELPE, 2019).

Algumas cidades brasi-leiras, cerca de $73,1 \%$ dos municípios, implementaram os sistemas de coleta seletiva, os quais abrangem a coleta domiciliar dos RSU, onde estes são separados por seus usuários em lixo úmido/orgânico e seco (PALOMBINI, CIDADE e JACQUES DE JACQUES, 2016; ABRELPE, 2019; BRASIL, 2010). Os resíduos úmidos são despejados pela população em contêineres alocados nas ruas e avenidas, onde são recolhidos pelas prefeituras e transportados diretamente para aterros e centros de compostagem. Já os resíduos secos são recolhidos pelo sistema de coleta seletiva em dias específficos, sendo posteriormente destinados a Centros e/ou Associações de Triagem. Os RSU nestes Centros de Triagem, são separados para fins de venda; isto é, os resíduos pós-classificados são vendidos a empresas que reciclam e utilizam como material secundário. Estes Centros são compostos geralmente por trabalhadores de baixa renda, os quais dependem dos Centros para seu sustento (PALOMBINI, 2015; PALOMBINI, CIDADE e JACQUES DE JACQUES, 2016).

Um dos materiais de maior abundância nestes Centros de Triagem são os polímeros. Entretanto, as embalagens poliméricas são consideradas uma preocupação ambiental mundial devido ao seu grande volume de consumo nos últimos anos e a forma inadequada de descarte. Segundo o Sindicato Nacional de Empresas de Limpeza Urbana (SELUR, 2019) o Brasil perde $\mathrm{R} \$ 5,7$ bilhões por ano por não reciclar os materiais poliméricos, onde grande parte desse problema é devido aos resíduos não serem descartados corretamente pela comunidade e nem por órgãos responsáveis pela coleta (MORENO e CIDADE, 2019). Além disso, a disposição do material nos produtos é outro fator importante para a difícil obtenção da reciclagem de polímeros no Brasil. Há um grande volume de embalagens sem potencial devido a fatores como a existência de multimateriais, de película aplicada, e/ou com excesso de impurezas. Muitas embalagens acabam tendo em sua composição uma variedade de materiais, como as embalagens alimentícias, que muitas vezes são aluminizadas juntamente com polipropileno, inviabilizando a separação destes nos Centros de Triagem (PALOMBINI, CIDADE e JACQUES DE JACQUES, 2016). Já quanto ao excesso de impurezas encontrados nas embalagens, é possível citar as cápsulas poliméricas de café, utilizadas em máquinas de diversas marcas do mercado nacional e internacional. Estas possuem potencial para a reciclagem, mas contém em seu interior rejeitos orgânicos de café, leite, achocolatados, chás, entre 
outros. Estes rejeitos deveriam ser retirados, pelos consumidores, antes do descarte no lixo doméstico, mas, muitas vezes, isto não é feito, dificultando assim a reciclagem.

Diversos polímeros, quando em forma de produtos de consumo, acabam por se tornar obsoletos e são descartados em um curto período, ou até mesmo posterior ao seu único uso (AL-SALEM et al., 2009). Estes, na maioria das vezes, não são biodegradáveis e levam centenas de anos para se decomporem, aumentando assim os riscos e impactos ambientais ao meio ambiente (Singh et al., 2017). Nesse sentido, tornou-se necessário, nos últimos anos, o uso de técnicas eficazes como a reciclagem e a reutilização de materiais de produtos descartados no lixo. Após seu consumo, os polímeros precisam atender à ordem de prioridade de redução de consumo, reutilização e reciclagem de resíduos gerados, tratamento de rejeitos e direcionamento a aterros. (BRASIL, 2010). Grande parte dos polímeros gerados vão para os aterros sanitários e/ou lixões, ou ainda acabam sendo descartados em rios e oceanos, ficando centenas de anos sem se degradar (PALOMBINI et. al. 2018). Algumas estimativas preveem cerca de 200 anos para alguns tipos de polímeros, gerando sobrecarga nos locais despejados e aumentando o impacto ambiental (SINGH et. al, 2017).

Durante o ano de 2015 foi assinado, no Brasil, por cerca de 20 Associações, o Acordo Setorial para Implementação de um Sistema de Logística Reversa de Embalagens em Geral, onde a meta inicial era recuperar $24,8 \%$ de materiais de alumínio, papel/papelão e polímeros (ABRELPE, 2019). No ano de 2017, no final da fase um do Acordo, foram geradas 21,153 toneladas por dia de polímeros, do qual apenas $8,2 \%$ foram recuperadas, representando um aumento de apenas 0,7\% desde o ano de 2012 (ABRELPE, 2019). Grande parte do problema é a falta de conhecimento da população brasileira, que de acordo com uma pesquisa realizada pelo Ipea (Instituto de Pesquisa Econômica Aplicada), em que 94\% dos brasileiros concordam que a forma correta de descarte é a separação dos lixos recicláveis e úmidos e 98\% reconhecem que este ato é importante para o futuro do planeta (IBOPE, 2018). Mas 75\% dos pesquisados, não fazem a separação dos lixos em suas residências e 66\% afirmam sequer saber sobre a coleta seletiva nas cidades (IBOPE, 2018). Quando perguntado sobre a reciclagem de polímeros, 77\% sabem que o material é reciclável (IBOPE, 2018).

Um dos princípios do design, segundo Manzini (2008), aplica-se na atuação do designer para a inovação social e sustentabilidade, a fim de desenvolver projetos na redução de impactos sociais, ambientais e econômicos ao longo de todo o seu ciclo de vida. Logo, o profissional pode atuar com o redesign ambiental do já existente, projetos de novos produtos ou serviços que substituam os atuais; projetos de novos produtos-serviços intrinsecamente sustentáveis e a proposta de novos cenários que correspondam ao estilo de vida sustentável (MANZINI, VEZZOLI, 2002). Também, um dos papéis fundamentais do designer é o de atuar na resolução de problemas, tais como a utilização de materiais que não possuem interesse comercial, como os polímeros das cápsulas de café.

Com isto, esta pesquisa tem como objetivo o estudo e uma possível conscientização aos consumidores que geram resíduos poliméricos, mostrando que é possível a reciclagem e/ou reutilização de embalagens problemáticas para o meio ambiente. Para isso, será utilizado nesta pesquisa, cápsulas poliméricas de café comercializadas no mercado, para a realização de um projeto aplicado ao desenvolvimento de produtos, enfatizando que com o descarte certo, as embalagens podem e devem ser recicladas, gerando possíveis aplicações e consequentemente renda as famílias dos Centros de Triagem.

\section{DESENVOLVIMENTO}

Para este estudo, devido à natureza experimental de escala reduzida, optou-se pela aplicação do processo no desenvolvimento de produtos com dimensões menores, como o caso de adornos. Inicialmente, limitou-se que as cápsulas de café descartadas iriam ser recicladas, mas se porventura algum resultado fosse insatisfatório, o estudo seria redirecionado para a reutilização do material. Por esta razão, utiliza-se o termo reciclagem e/ou reutilização.

A metodologia utilizada para o projeto foi a de Löbach (2001) de forma adaptada aos objetivos propostos. Foram seguidas quatro etapas principais, descritas abaixo:

- Fase de Preparação: conhecimento do problema em torno do descarte de RSU, definição dos objetivos, coleta e análise de informações sobre as cápsulas de café e seu processo de reciclagem.

- Fase de Geração e Avaliação: Com as informações levantadas na primeira fase, parte-se primeiramente para e geração de ideias, para o desenvolvimento de produtos com a utilização de cápsulas de café. Nesta fase, será levado em consideração e avaliado, para o processo criativo dos produtos, aspectos relacionados à execução do método de reciclagem, o qual será realizado de forma artesanal. Para isso, no processo de criação, alguns aspectos terão que ser levados em consideração para a execução dos desenhos, tais como dimensões reduzidas, formatos simplificados, sem a presença de cantos pontiagudos, por exemplo, e peças menos complexas. - Fase de Realização e Avaliação: Compõe a concepção do projeto, através de processos artesanais e equipamentos mecanizados de pequeno porte. Pretende-se 
efetuar o processo de reciclagem através de um forno Mufla, com a fundição das cápsulas. Estas serão fundidas em um molde de silicone. Com o desenvolvimento da fase de realização, todos os passos serão avaliados para prosseguimento e conclusão do projeto. Caso haja a necessidade, novas fases serão adicionadas ou retomadas.

\subsection{Cápsulas de Café}

Para este projeto, foram utilizados os resíduos descartados de duas marcas de cápsulas de café existentes no mercado, denominadas neste estudo de "Marca A" e "Marca B". Estas são oriundas do lixo doméstico de empresas, centros escolares e ambientes domiciliares.

As cápsulas poliméricas recolhidas encontravam-se com seus rejeitos em seus interiores, sendo retirados com a ajuda de ferramentas de corte para a posterior higienização das peças. Para a remoção dos rejeitos orgânicos, tais como restos de café, leite, achocolatado, chás, entre outros, foi preciso efetuar uma desmontagem das cápsulas, sendo utilizados luvas e óculos para a proteção. Por se tratar de amostras de duas marcas diferentes, achou-se necessário efetuar a desmontagem separadamente das mesmas, para fins de análise de materiais e estrutura.

Para isso, primeiramente foi efetuado um corte para a retirada das tampas das cápsulas das duas marcas. Com a desmontagem das amostras da Marca A, notou-se que tanto as cápsulas de café, quanto as de leite, achocolatado e chá, possuíam dois filtros, um alocado na parte superior, rente à tampa, e o outro na parte inferior (Figura 01). Para as amostras da Marca B, que continham resíduos de leite e achocolatado, foi encontrada uma espécie de filtro no fundo do interior, o qual tem contato com o material interno e a saída do líquido quando introduzido nas máquinas de café. Já nas cápsulas que contém apenas café, além deste filtro, havia a existência de uma segunda tampa polimérica com microfuros, estes tendo a finalidade de distribuir a água.

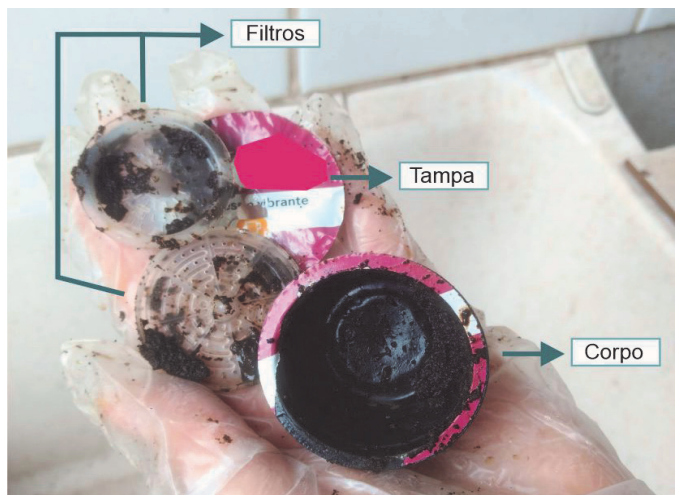

Figura 01 - Partes da cápsula de café da Marca A Fonte: Autores
Com a variedade de componentes encontrados no interior das cápsulas, foi necessária a realização de uma análise de qual ou quais materiais compunham as amostras. O resultado desta análise objetiva auxiliar na determinação de parâmetros para o processo de reciclagem. Para isto, foi utilizado a espectroscopia de infravermelho com transformada de Fourier (FT-IR). Esta análise é considerada uma das mais importantes técnicas experimentais para a caracterização de materiais, em termos de identificação e/ou determinação de características estruturais (CALLISTER, 2016). O equipamento utilizado nesta foi o PerkinElmer ${ }^{\oplus}$, Spectrum 100, com biblioteca de polímeros. Todas as partes que compõem as cápsulas das duas marcas existentes foram analisadas, tais como as tampas, os corpos, os filtros e as tampas secundárias com microfuros. Com as análises, foi averiguado que todas as amostras indicaram polipropileno (PP) em sua composição. Segundo Lefteri (2013) e Ashby e Johnson (2011), o PP é um material de fácil reciclabilidade, densidade baixa e ponto de fusão em torno de $160^{\circ} \mathrm{C}$. No ano de 2017 , no Brasil, cerca de 2.000 toneladas/dia foram coletadas de polipropileno (ABRELPE, 2019).

Com a coleta, desmontagem e averiguação da composição das partes das cápsulas, partiu-se para as etapas correspondentes ao processo criativo do projeto.

\subsection{Processo Criativo}

Para a geração das alternativas, optou-se pela inserção dos próprios resíduos das cápsulas de café no ambiente de criação, onde estes seriam utilizados como elementos de inspiração para este processo, observando-o seus formatos e composições. Para a geração do processo, foi utilizada uma fotografia da higienização e separação das cápsulas recolhidas, como painel temático, proporcionando assim, elementos visuais para a concretização das ideias. Como mencionado anteriormente, em virtude de o processo de reciclagem ser realizado de forma artesanal, será levado em consideração alguns aspectos de dimensionamento e simplificação de formas. Na Figura 02, é exemplificado o processo de criação do projeto, através da simplificação das formas e da observação do posicionamento das peças na imagem.

$\mathrm{Na}$ figura evidencia-se através de setas as partes onde foram executadas as simplificações. A partir das primeiras ideias, as formas foram sendo aperfeiçoadas, pensando nos aspectos de arredondamento dos cantos, para a não obtenção de partes pontiagudas e, também, buscando o modo como as cápsulas estavam dispostas na imagem, o de agrupamento em círculos. 

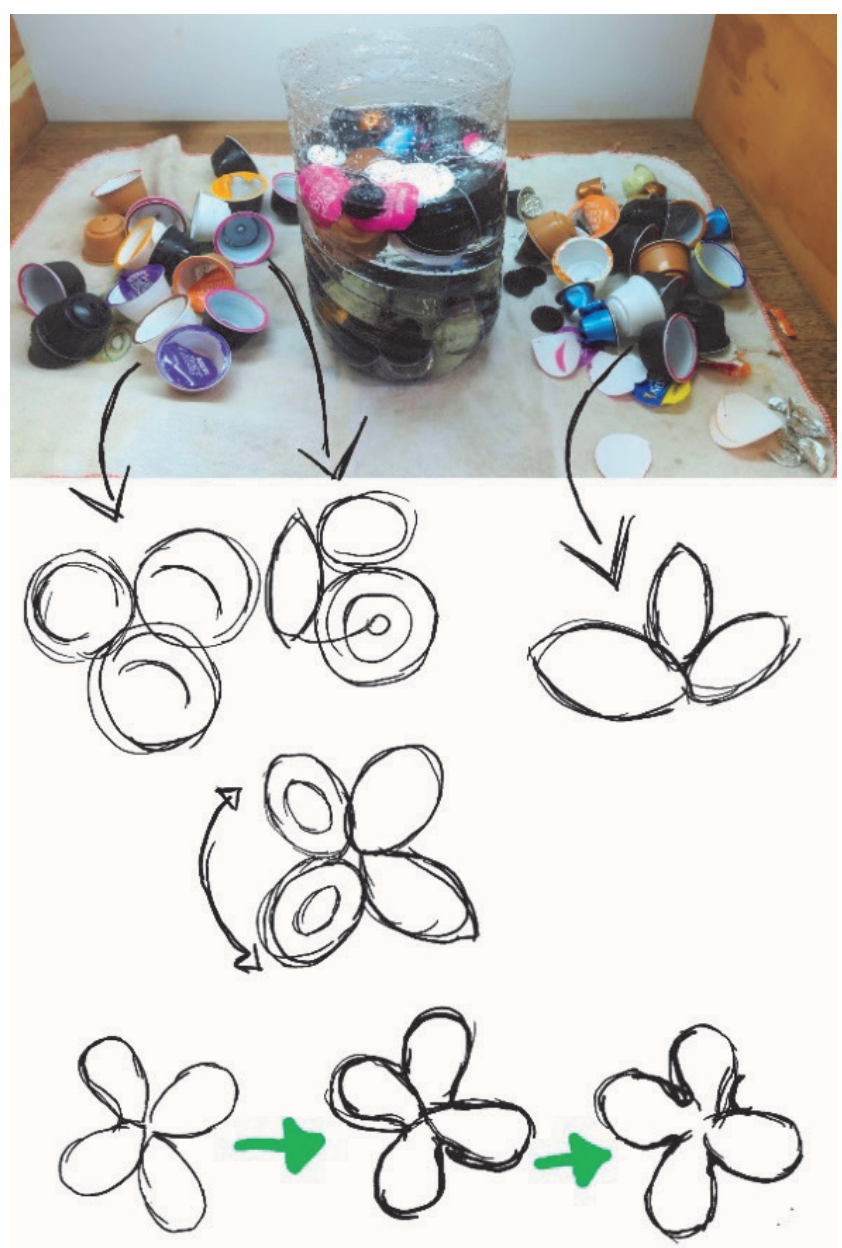

Figura 02 - Processo criativo do projeto Fonte: Autores

Ao final do processo, chegou-se em uma forma arredondada, com uma espécie de movimento em sua composição. Esta foi vetorizada e dimensionada em um software de desenho vetorial para a realização das etapas seguintes. Com o dimensionamento, delimitou-se que a peça criada, dependendo do resultado da reciclagem, poderia ser um acessório de cabelo, como um prendedor. Isto devido às suas dimensões e por estar em uma região menos exposta, diminuindo seus requisitos de resistência estrutural, por se tratar de uma peça reciclada.

\subsection{Concepção}

Com a forma definida, partiu-se para a fabricação do molde de silicone para a posterior reciclagem das cápsulas poliméricas de café. Para isso, primeiramente foi fabricado um modelo em madeira, através da vetorização, utilizando o processo de usinagem CNC (Figura 03). Após, a madeira usinada foi lixada para deixar a superfície lisa e não ter imperfeições no molde.
Para a construção do molde de silicone, este foi acoplado em uma forma metálica. Ao centro desta forma, foi adicionado o modelo em madeira sendo, após, coberto por mais camadas de silicone. Ao ser preenchido totalmente na forma, o silicone foi levado para uma vulcanizadora de marca Zezimaq ${ }^{\oplus}$, a uma temperatura de $180^{\circ} \mathrm{C}$, por aproximadamente 1 hora. Após seu resfriamento, a peça de madeira foi retirada do molde de silicone.

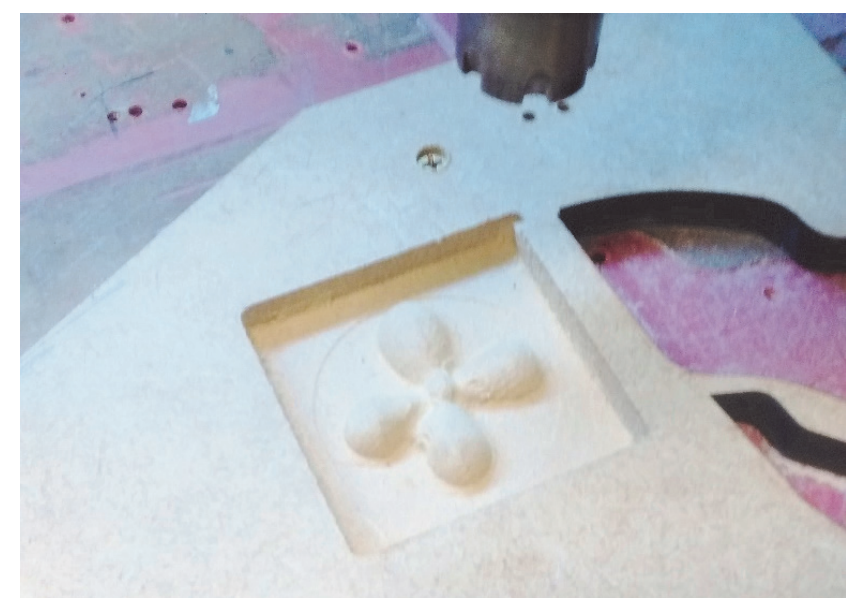

Figura 03 - Processo de usinagem em madeira da peça criada Fonte: Autores

Com o molde fabricado, foi possível dar andamento a fundição com as cápsulas, a fim de auxiliar em um novo destino a um material tão problemático para o meio ambiente. Primeiramente, para o início do processo de fundição, iniciou-se com o corte das partes do corpo da cápsula, em quadrados de aproximadamente $1 \times 1 \mathrm{~cm}$. Optou-se pelo corte do corpo por possuir uma área maior e mais lisa. Os pedaços cortados foram separados por cor com a finalidade de aplicá-los na criação.

Para o prendedor de cabelo, foram executados quatro testes de averiguação do comportamento do polímero, sendo utilizado um desmoldante no silicone para auxiliar na retirada das peças prontas. A fundição do polímero foi feita em forno Mufla da marca Zezimaq ${ }^{\circledR}$, no qual, para a temperatura dos experimentos, levou-se em consideração o ponto de fusão do polipropileno, o qual inicia-se por volta de $160^{\circ} \mathrm{C}$. Para a fundição do primeiro teste, foram colocados no molde de silicone os pedaços das cápsulas de café até passar da borda do molde, utilizando as cápsulas de tonalidades preta e branca (Figura 04). O molde foi colocado no forno em temperatura de $170^{\circ} \mathrm{C}$, por 30 minutos. Após este tempo, contudo, notou-se que as peças não haviam apresentado sinal de fundição. Desse modo partiu-se para um aumento da temperatura, no segundo teste. 


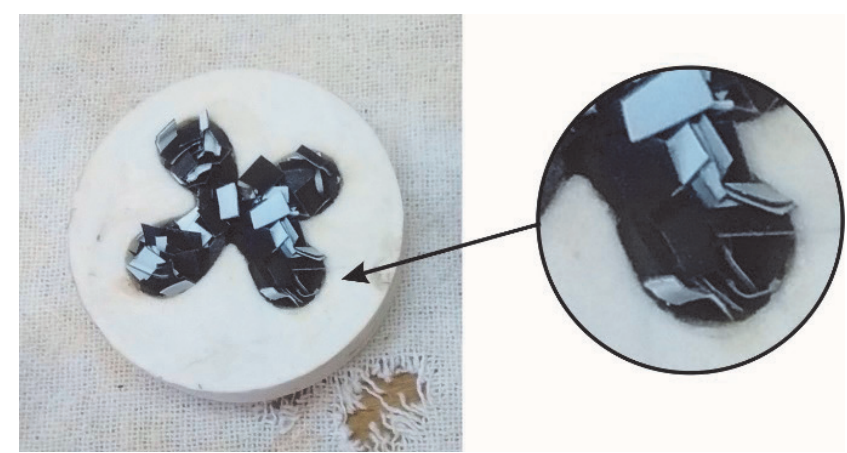

Figura 04 - Primeiro teste: alocação dos pedaços das cápsulas Fonte: Autores

No segundo teste, o mesmo molde com pedaços foi levado ao forno pré-aquecido em $250^{\circ} \mathrm{C}$ por 30 minutos. Após este período, o molde foi retirado do forno e deixado esfriar até atingir a temperatura ambiente. Com o esfriamento do molde, notou-se a existência de buracos na superfície da peça. Outro aspecto observado foi que a região com os pedaços das cápsulas na tonalidade branca ficou com um aspecto queimado, ocasionando a quebra da peça ao ser retirada do molde (Figura 05). Isto se deve, provavelmente, pelo excesso de temperatura programada no forno.

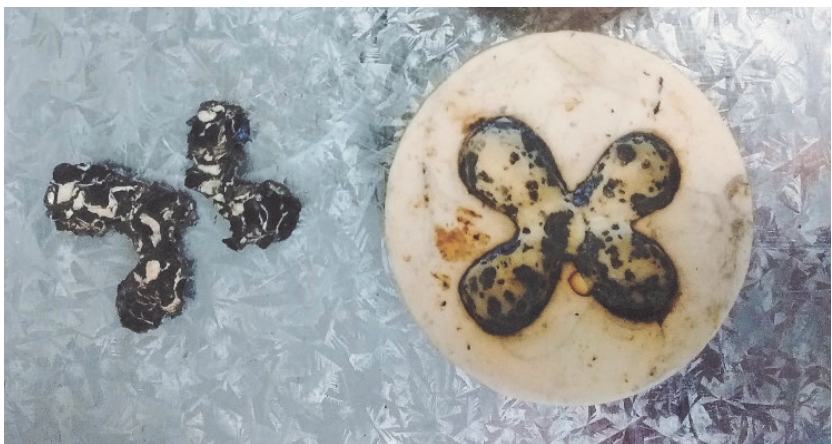

Figura 05 - Segundo teste: quebra da peça Fonte: Autores

Para o terceiro teste foi utilizada uma temperatura de forno um pouco mais baixa. Com isto, foram alocados os pedaços das cápsulas apenas no fundo do molde, em uma primeira camada, a uma temperatura de $200^{\circ} \mathrm{C}$ por 15 minutos, como o visualizado na Figura 06. Em seguida, foi adicionada uma segunda camada de polímeros cortados com a mesma temperatura e tempo, e, após, uma terceira camada. Com esta terceira sobreposição, notou-se que seria necessária uma quarta camada, nas mesmas condições anteriores. Ao retirar do forno notou-se a presença de cavidades na superfície da peça, causadas, provavelmente, pelos espaços que ficaram entre os pedaços das cápsulas.

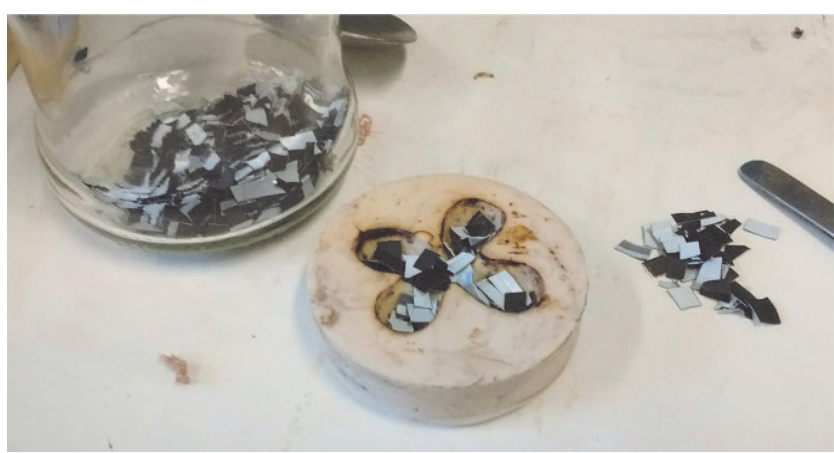

Figura 06 - Segundo teste: alocação da primeira camada Fonte: Autores

No quarto teste executado, foi feito o mesmo processo anterior, mas a fim de evitar as cavidades na superfície da peça, foi utilizada uma pinça para pressionar os fragmentos já derretidos antes de colocar a camada seguinte. Com esse teste, obteve-se um resultado melhor que os anteriores, com uma superfície lisa. Este foi executado, também, com todas as tonalidades das cápsulas, sendo elas uma peça preta e branca, uma somente branca e outra preta, branca e marrom (Figura 07), para obter-se um efeito diferenciado.

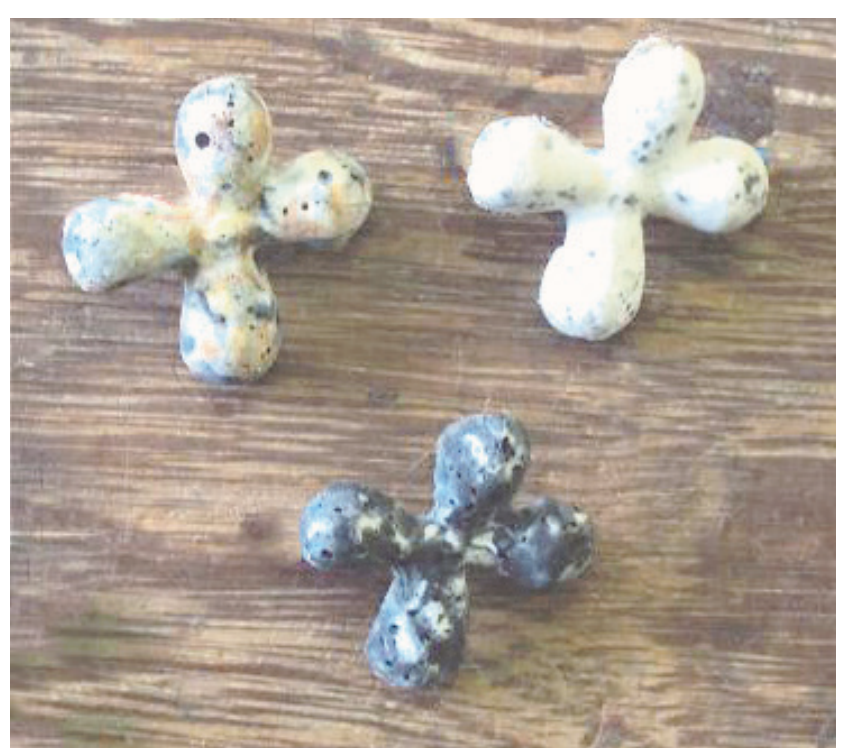

Figura 07 - Testes executados com as cápsulas Fonte: Autores

Por fim, também foi executado um teste com as amostras das tampas das cápsulas (Figura 08). Assim como nos testes anteriores, o molde foi revestido previamente com um desmoldante e o material cortado em pedaços foi adicionado em camadas. A primeira camada foi posta no forno por 15 minutos a uma temperatura de $200^{\circ} \mathrm{C}$. Entretanto, observou-se que esta camada não se fundiu. Com isto, a segunda camada foi colocada por 35 minutos 
a $200^{\circ} \mathrm{C}$ e obteve-se o mesmo resultado. Optou-se, então, por aumentar a temperatura para $215^{\circ} \mathrm{C}$, para a execução de uma terceira camada, por 20 minutos de forno. Entretanto, este processo também não derreteu e resultou em uma aparência pegajosa entre os pedaços, como é visualizado na Figura $08 \mathrm{~A}$. Com o não derretimento das camadas do polímero da tampa, considerou-se que algo estaria prejudicando a fundição. Com isto, optou-se por analisar a tampa das cápsulas de café para verificar se poderia haver algum aspecto que estava dificultando a fundição, uma vez que a espessura do polímero nesta região é maior do que a do corpo da cápsula, além de esta ser a passagem do jato de água para o contato com o interior da amostra. Com o auxílio de uma ferramenta cortante para a raspagem da tampa da cápsula, foi verificada a existência de uma película (Figura 08 B).
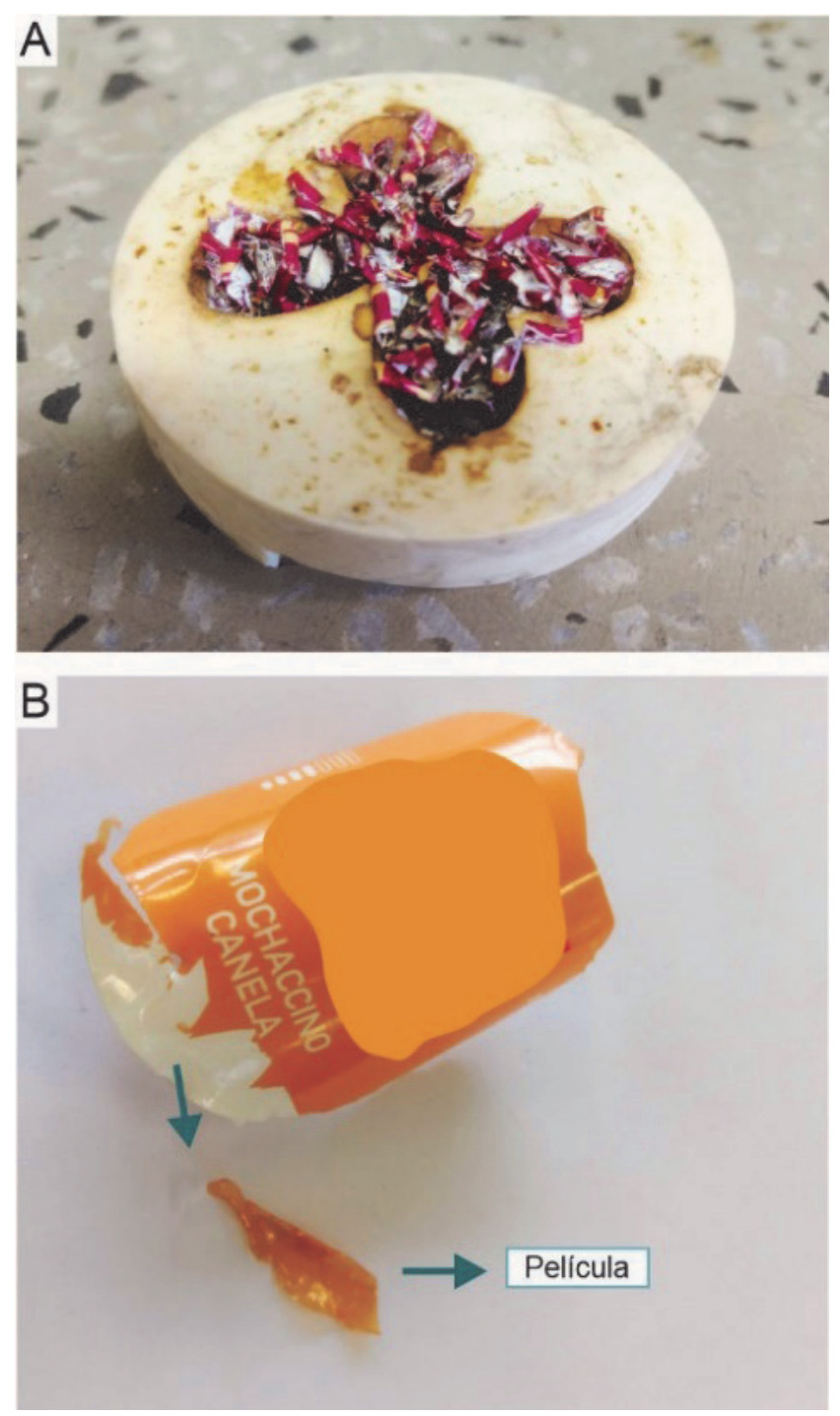

Figura 08 - Testes e análise: (A) resultado dos pedaços não derretidos por completo, e (B) existência de película na tampa da cápsula de café.

Fonte: Autores
O PP é um polímero de relativa fácil reciclagem, mas em alguns casos, uma película pode estar incluída ao material, tornando o processo, assim, mais difícil de ser realizado (ASHBY e JOHSON, 2011). A película é aplicada como revestimento para conferir determinadas propriedades adicionais, como, por exemplo, maior resistência mecânica, maior opacidade e maior impermeabilização. Por tanto, as cápsulas de café, leite, achocolatados e chás, possuem a aplicação deste componente em suas tampas para uma maior proteção da integridade da cápsula e do produto alimentício, contudo acaba interferindo na reciclagem deste componente. Por esta razão, para efetuarmos os objetivos deste estudo, optou-se pela reutilização somente das tampas das cápsulas poliméricas de café, ou seja, sem a realização de um processo de fundição.

Para este processo, algumas tampas foram selecionadas para serem introduzidas ao projeto como "elementos decorativos" através da junção de um outro material, a resina epóxi. Para isso, buscou-se elencar os formatos iniciais das gerações do processo criativo da reciclagem do prendedor de cabelo, para ter o mesmo motivo inserido. As tampas então, foram recortadas com uma tesoura em formatos circulares, meio círculos e elipses. E com as sobras destes recortes, foram feitos novos formatos, mais retangulares e quadrados. Com os recortes efetuados das tampas das cápsulas de café, partiu-se para o processo de geração de alternativas (Figura 09) para averiguação do formato e disposição destes com a resina epóxi.

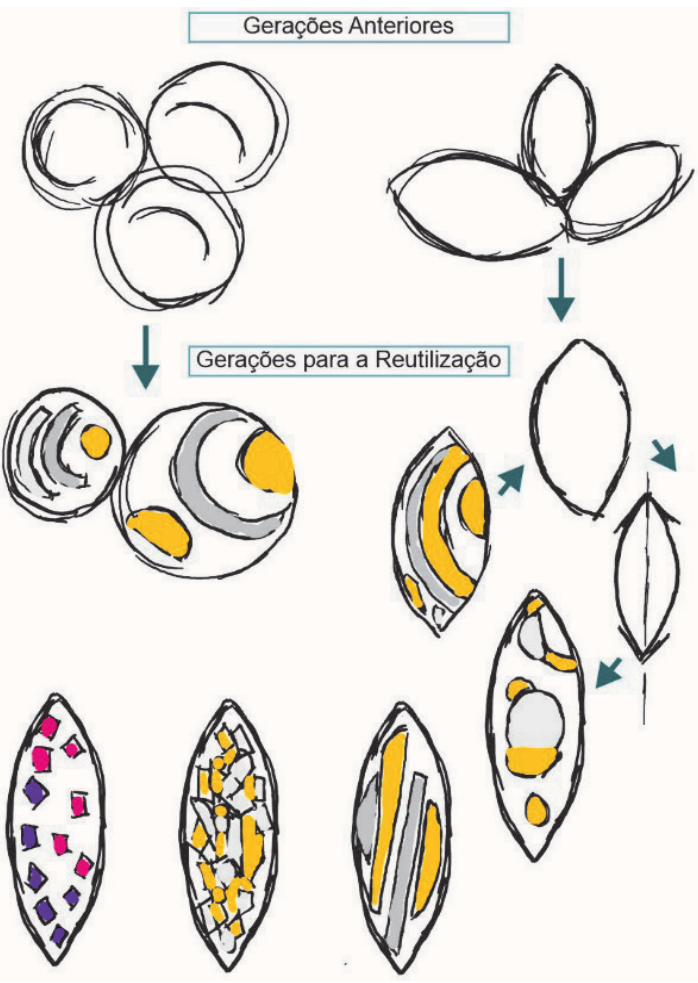

Figura 09 - Processo criativo da reutilização das tampas, contendo a evolução do processo com as variaçōes dos recortes.

Fonte: Autores 
Após a geração, foram fabricadas 5 peças, onde primeiramente, foi executado um molde no formato delimitado nas gerações das alternativas, para a acomodação dos recortes das tampas e posterior aplicação da resina. Este foi produzido com um chapa espessa de alumínio e fita adesiva. Já a resina epóxi, foi misturada a um catalisador, em uma proporção de 35 gotas para $100 \mathrm{ml}$ de resina, conforme a descrição do fabricante. A resina foi preparada e vertida nos moldes com os recortes dispostos, como visualizado na Figura 10. Os recortes das tampas das cápsulas foram posicionados ao fundo do molde e de forma inversa (Figura $10 \mathrm{~A}$ ). Quando desmoldada a peça, os desenhos pensados na geração de alternativas ficaram na parte superior da resina (Figura $10 \mathrm{~B}$ ).
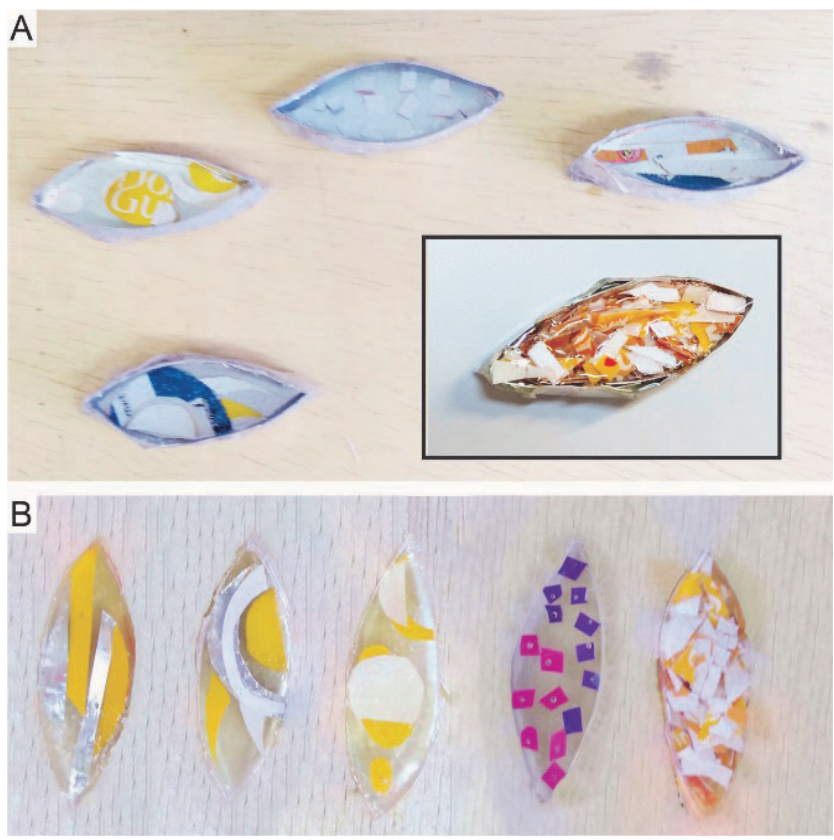

Figura 10 - Produção das peças em resina: (A) recortes posicionados nos moldes, com detalhe de uma das peças, e (B) peças fabricadas.

Fonte: Autores

Em seguida, com as peças fabricadas, analisou-se que estas possuíam uma alusão com gemas utilizadas em joias. Por esta razão, direcionou-se o projeto de reutilização a concepção de um bracelete em prata (Ag 950) com uma peça de resina com as tampas das cápsulas em destaque. Como o objetivo deste estudo é a valorização do rejeito de cápsulas de café por meio de reciclagem e reutilização, delimitou-se que o bracelete teria seu formato simplificado, sem a adição de componentes rebuscados justamente para dar maior destaque à peça polimérica. Com isso, foi utilizado somente um fio, para a circunferência do bracelete e para o encaixe da peça em resina, como o exemplificado no processo de fabricação da Figura 11.
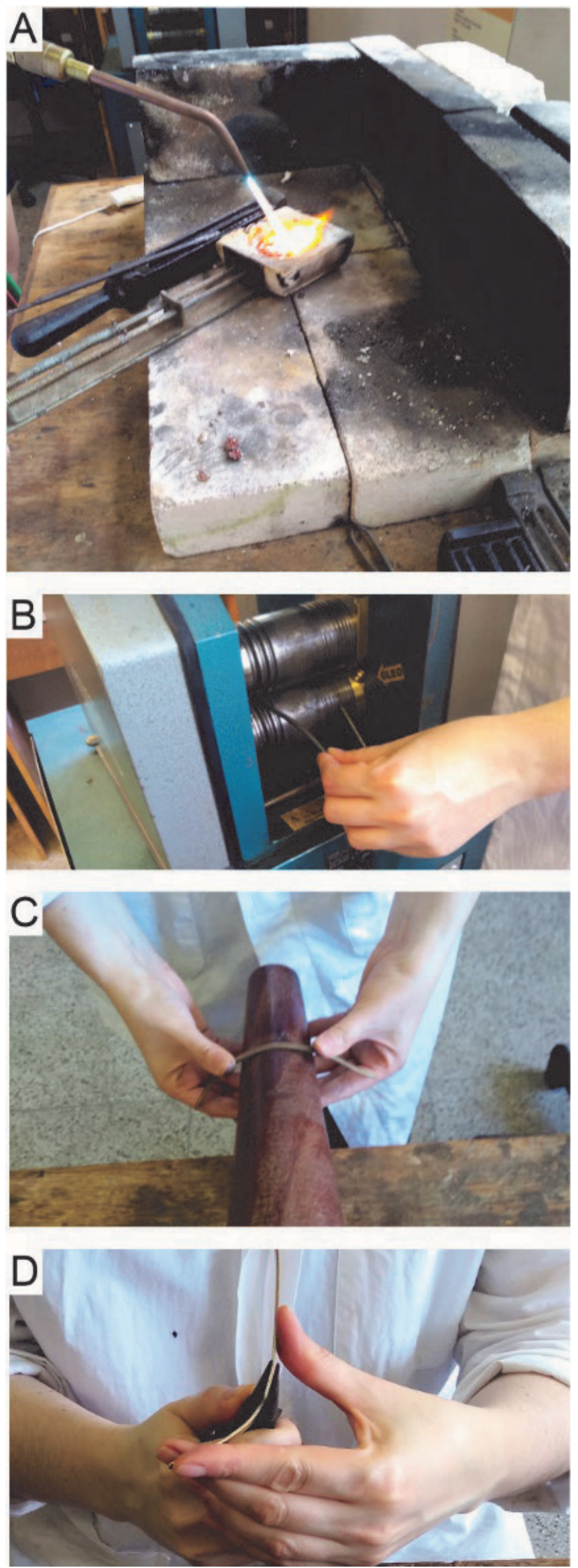

Figura 11 - Processo de fabricação da parte metálica Fonte: Autores 
Para este processo de fabricação, primeiramente fundiu-se uma liga de prata, sendo vertida em uma lingoteira (Figura 11 A). Com o lingote de prata, passou-se para a laminação para a obtenção de um fio (Figura 11 B). Este, foi serrado em duas partes, onde uma foi martelada para a obtenção do formato elíptico, e a outra parte foi ajustada através de alicates para ser utilizada no encaixe da peça de resina (Figura 11 C e D).

Posteriormente, já com o formato definido, as duas peças foram limadas e soldadas uma à outra. Com as partes unidas, foi necessário limá-las novamente para retirar o excesso de solda, sendo lixadas em seguida. Após, o bracelete passou por um processo de polimento para dar um brilho final. Por fim, as peças resultantes de resina foram testadas para a verificação de qual se comportaria esteticamente melhor, e uma foi delimitada para o uso no bracelete. Esta então, foi encaixada ao metal, do mesmo modo que a cravação de uma gema.

\section{RESULTADOS}

Com o desenvolvimento do projeto de reciclagem do corpo das cápsulas poliméricas de café e a reutilização das tampas, são apresentados os resultados alcançados para os dois produtos.

Primeiramente, quanto ao prendedor de cabelo fabricado a partir da reciclagem do corpo das cápsulas, tem-se que com os ajustes de temperatura do forno adequados para este tipo de material é possível obter-se uma peça homogênea e lisa, sem grandes imperfeições. Na Figura 12 , é possível visualizar o resultado dos prendedores de cabelo, com os diferentes testes executados, em uma ambientação do seu uso. Estes prendedores foram resultantes da fundição das cápsulas de tonalidades branca e preta; somente branca; e branca, preta e marrom.

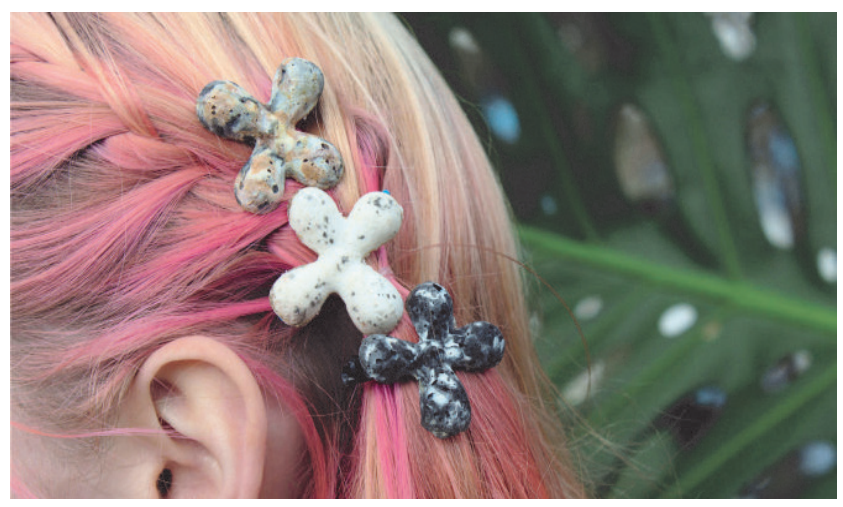

Figura 12 - Resultado dos três prendedores de cabelo em uso Fonte: Autores

Já o resultado adquirido com a reutilização das tampas das cápsulas, com o bracelete, pode ser visualizado na Figura 13. O objetivo da fabricação desta peça foi dar destaque à peça de resina com os recortes das tampas das cápsulas de café (Figura 13 A e B). Acredita-se que esta ênfase foi alcançada, justamente pelo posicionamento da resina com os recortes das tampas na parte central da joia, e pela utilização de formas simplificadas do material em prata. Desta maneira a visualização da reutilização das cápsulas de café fica em evidência ao olhar humano, transmitindo assim um certo interesse e curiosidade para quem as olha.
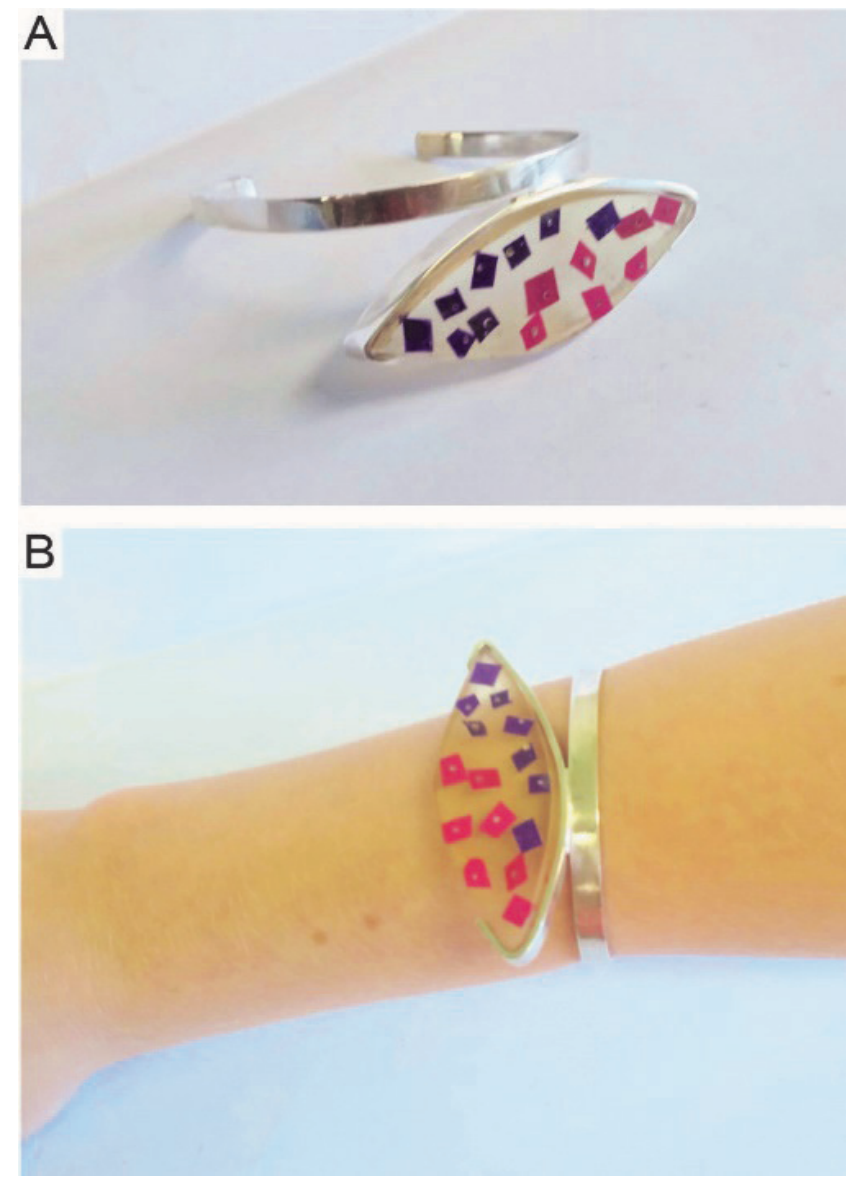

Figura 13 - Resultado do bracelete (A), e em (B) o uso da peça Fonte: Autores

\section{CONSIDERAÇÕES FINAIS}

Cada vez mais um dos papéis dos designers é a responsabilidade de projetar de forma consciente e sustentável. Com isto, segundo ABRELPE (2019), com a tendência de crescimento na geração de resíduos sólidos urbanos no país nos próximos anos, o Brasil alcançará uma geração anual de 100 milhões de toneladas por volta de 2030. Com esta estimativa, os consumidores precisam ser conscientizados, tanto pelo aumento do consumo de produtos, e o que isso vai ocasionar, quanto pela forma correta de descartá-los.

Um dos objetivos deste artigo, além do projeto alcançado de dois adornos, é uma possível conscientização aos consumidores que geram resíduos poliméricos, 
mostrando que é possível a reciclagem e a reutilização de embalagens problemáticas para o meio ambiente. Com o descarte certo e a retirada dos rejeitos no interior das cápsulas, as embalagens podem e devem ser recicladas, gerando possíveis aplicações e consequentemente renda aos trabalhadores e famílias dos Centros de Triagem, além de menor impacto ambiental.

No mercado de cápsulas de café existem outras marcas e materiais existentes, como as de alumínio. Estas, por sua vez, possuem um maior potencial para a reciclagem, em virtude do próprio valor do material secundário, em comparação aos resíduos poliméricos. Ainda, uma vez que as próprias fabricantes tendem a fazer o recolhimento dos resíduos das cápsulas de alumínio em diversos postos espalhados pelas cidades brasileiras, elas nem acabam chegando aos Centros de Triagem municipais. Isso ressalta que quanto maior o interesse econômico no material descartado, maior é sua probabilidade de ser reciclado, o que amplia ainda mais a problemática com resíduos poliméricos, visto que suas resinas virgens já possuem um valor muito baixo.

Para o mercado e o meio ambiente, atitudes de incentivo à reciclagem e, anteriormente, ao descarte adequado, favorecem o fechamento do ciclo de um produto, ocasionando o não desperdício de sua embalagem. Cabe ao designer, portanto, a tarefa de facilitar este processo, seja ao propor novos produtos com meios mais facilitados de serem reciclados, ou estimular a reciclagem de materiais de menor interesse intrínseco. Quanto à esfera pública, é importante a manutenção e incentivo de práticas de educação à população consumidora para separarem os seus resíduos de maneira que contribua a sua reciclagem em Centros de Triagem.

\section{AGRADECIMENTOS}

Ao CNPq pelo apoio financeiro através de bolsas de Iniciação Científica, Projeto Universal MCT/CNPq 028/2018, intitulado: Do luxo ao lixo: desenvolvimento de subsídios para aplicação de resíduos sólidos urbanos na joalheria. Agradecimentos ao Laboratório de Design e Seleção de Materiais da Universidade Federal do Rio Grande do Sul (LdSM/UFRGS), pela disponibilização do equipamento de FT-IR.

\section{REFERÊNCIAS}

ABRELPE. Panorama dos resíduos sólidos no Brasil. 2019. Disponível em:<http://abrelpe.org.br/pdfs/panorama/panorama_abrelpe_2019.pdf $>$ Acesso em: 1 maio. 2020.

AL-SALEM, S. M.; LETTIERI, P.; BAEYENS, J. Recycling and recovery routes of plastic solid waste (PSW): A review. Waste Management, v.29, p. 2625-2643, 3 July 2009. DOI: 10.1016/j.wasman.2009.06.004

ASHBY, M.; JOHNSON, K. Materiais e Design - Arte e ciências da seleção de materiais no design de produto. Rio de Janeiro: Elsevier, 2011.

BARELLI, B. G. P. Design para a sustentabilidade: mo $7-$ delo de cadeia produtiva do bambu laminado co $\neg$ lado (BLC) e seus produtos. 2009. 131 f. Dissertação (Mestrado - Programa de Pós-Graduação em Design) - Universidade Estadual Paulista "Júlio de Mesquita Filho", Bauru, 2009.

BRASIL. LEI No 12.305 DE 2 DE AGOSTO DE 2010. Institui a Política Nacional de Resíduos Sólidos; al $\neg$ tera a Lei no 9.605, de 12 de fevereiro de 1998; e dá outras providências. Diário Oficial [da] República Federativa do Brasil. Brasília, DF, 2 ago. 2010.

CALLISTER; D., J. W. Fundamentos da ciência e engenharia de materiais: uma abordagem integrada. 2a. ed. Rio de Janeiro: LTC Editora, 2006.

CARVALHO, T. C. M. B.; XAVIER, L. H. Gestão de resí-duos eletroeletrônicos. Rio de janeiro: Elsevier, 2014.

IBOPE. Desinformação é maior dificuldade para reciclagem no Brasil 2018. Disponível em: <https://www. ibopeinteligencia.com/noticias-e-pesquisas/desinformacao-e-maior-dificuldade-para-a-reciclagem-no-brasil/ > Acesso em: 19 março 2020.

LEFTERI, C. Materials for design. Laurence King Publishing, 2013.

LÖBACH, B. Design Industrial: bases para a configuração dos produtos Industriais. São Paulo: Editora Blucher, 2001.

MANZINI, E. Design para a inovação social e sustentabilidade: comunidades criativas, organizações colaborativas e novas redes projetuais. Rio de Janeiro: E-papers, 2008. (Cadernos do Grupo de Altos Estudos; v.1).

MANZINI, E.; VEZZOLI, C. Desenvolvimento de produtos sustentáveis: os requisitos ambientais dos produtos industriais. São Paulo: EDUSP, 2002.

MORENO, S. N. S.; CIDADE, M. K. Sustentabilidade e Joalheria: Reciclagem de Eps para Aplicação em Joias. MIX Sustentável, [S.I.], v. 5, n. 4, p. 27-39, nov. 2019. DOI: https:// doi.org/10.29183/2447-3073.MIX2019.v5. n4. 27-39.

PALOMBINI, F. L.; CIDADE, M. K.; JACQUES DE JACQUES, J. How sustainable is organic packaging? A design me $\neg$ thod for recyclability assessment via a social perspec $\neg$ tive: A case study of Porto Alegre city (Brazil). 
Journal of Cleaner Production, v. 14, p. 2593-2605, 4 novem $\neg$ ber. 2016. DOI: 10.1016/j.jclepro.2016.11.016

PALOMBINI, F. L., Design de equipamento híbrido para o reprocessamento de resíduos poliméricos: aglutinador e moinho de facas. 2015. 256 f. Trabalho de Conclusão de Curso - Universidade Federal do Rio Grande do Sul, Porto Alegre, 2015.

PALOMBINI, F. L.; DEMORI, R.; CIDADE, M. K.; KINDLEINJ JR., W.; JACQUES DE JACQUES, J. Occurrence and recovery of small-sized plastic debris from a Brazilian beach: characterization, recycling, and mechanical analysis. Environmental Science and Pollution Research, v.25, p 26218-26227, 27 june 2018. DOI: https://doi. org/10.1007/s11356-018-2678-7

Sindicato Nacional de Empresas de Limpeza Urbana (SELUR). Índice de Sustentabilidade da Limpeza Urbana para os municípios brasileiros. 2019. Disponível em: https://selur.org.br/publicacoes/islu-indice-de-sustentabilidade-da-limpeza-urbana-para-os-municipios-brasileiros-3a-edicao-2019/.Acesso em: 13 mar. 2020.

SINGH, N.; HUI, D.; SINGH, R.; AHUJA, I.P.S.; FEO, L.; FRANTERNALI, F.. Recycling of plastic solid waste: a state of art review and future applications. Composites Part B Engineering, v.115, p. 409-422, 2020, 15 april 2017. DOI: http://dx.doi.org/10.1016/j. compositesb.2016.09.013.

\section{AUTORES}

ORCID: https://orcid.org/0000-0002-1318-8327

AMANDA MELCHIORS | Universidade Federal de Santa Maria - UFSM | Desenho Industrial | Santa Maria - RS, Brasil | Correspondência para: Av. Roraima, 1000, prédio 40, sala 1136 | e-mail: amandamelchiors@gmail.com

ORCID: https://orcid.org/0000-0002-2822-5055

ANA PAULA PALHANO | Universidade Federal de Santa Maria - UFSM | Desenho Industrial | Santa Maria - RS, Brasil | Correspondência para: Av. Roraima, 1000, prédio 40, sala 1136 | e-mail: aninhappalhano@gmail.com

ORCID: https://orcid.org/0000-0001-5893-383X

MARIANA KUHL CIDADE, Dra. | Universidade Federal de Santa Maria - UFSM | Departamento de Desenho Industrial| Santa Maria - RS, Brasil | Correspondência para: Av. Roraima, 1000, prédio 40, sala 1136 | e-mail: mariana.cidade@ufsm.br

\section{COMO CITAR ESTE ARTIGO}

MELCHIORS, Amanda; PALHANO, Ana Paula; CIDADE, Mariana Kuhl. Estudo de Reciclabilidade e Reutilização de Cápsulas Poliméricas de Café. MIX Sustentável, [S.I.], v. 6, n. 4, p. 93-104, ago. 2020. ISSN 24473073. Disponível em:<http://www.nexos.ufsc.br/index.php/ mixsustentavel>. Acesso em: dia mês. ano. doi:https:// doi.org/10.29183/2447-3073.MIX2020.v6.n4.93-104.

DATA DE ENVIO: 25/05/2020

DATA DE ACEITE: 01/07/2020 
